\title{
Ischaemic heart disease in England and Wales around the year 2000
}

\author{
C Osmond, D J P Barker
}

\begin{abstract}
Study objective-The aim was to predict death rates from ischaemic heart disease in England and Wales during the next 20 years. Study design-Age and sex specific death rates for 1968-1987 were used to predict national and regional trends until 2007.

Setting-The nine standard regions of England and Wales.

Results-There will be a large fall in deaths from ischaemic heart disease. The fall will be greater in men and women below 65 years of age. There will, however, be a sharp worsening of the north/south divide. The largest fall in any region will be in Wales.

Conclusions-The campaign to change the national diet should give highest priority to the northern regions. Because infant growth is inversely related to adult risk of ischaemic heart disease, the poor growth of young children in some northern areas is a cause for concern.
\end{abstract}

Death rates from ischaemic heart disease are now falling in Britain, ${ }^{1}$ but they remain high in comparison with other countries. ${ }^{2}$ Future rates can be predicted from recent trends. This prediction must distinguish changes in successive generations from other sources of year to year variation. We present predicted rates for England and Wales, in men and women, in each age group and within each region, into the next century.

\section{Methods}

We abstracted numbers of deaths from ischaemic heart disease (International Classification of Diseases codes 410-414 in 8th and 9th revisions) and population sizes from 1968 to 1987 for England and Wales and for the nine standard regions by age and sex. These data were used to predict future death rates, allowing for cohort (generation) effects. The statistical model used for prediction partitioned the age and sex specific rates for 1968 to 1987 according to age, year of death, and cohort. ${ }^{3}$ The year of death and cohort components were extended into the future, and then combined to predict age specific death rates for 1988 to 2007.

We calculated regional rates for deaths in middle age, which is by convention from 45 to 64 years. These were directly standardised to the European standard population, ${ }^{4}$ and are presented as mortality ratios based on the figure of 100 for England and Wales.
Results

The figure shows age specific death rates during $1968-87$ by year of birth. Rates among men fell progressively at all ages in generations born from 1928 onwards. Similarly among women rates fell in generations born from 1933 onwards. This demonstrates a cohort effect.

Table I shows death rates during 1968-87 and predicted rates for 1988-2007. Rates will fall in both men and women and in each age group. They will fall more in younger than older people. Up to 2003-7 there wil be a $43^{\circ}$ of fall in men aged 45-49 years in relation to 1983-7 rates. The fall at ages $65-69$ will be $25^{\circ}$. The corresponding figures for women will be $44^{\circ}{ }_{0}$ and $18^{\circ}$.

Table II shows observed and predicted mortality ratios by region among middle aged people. There will be a widening in regional differences. The highest death rates will continue to be in the three northern regions, but their ratios to the national average will increase. A large rise in the north west will take the ratio to 137 . The ratios in both midland regions will rise to exceed 100 . The lowest death rates will continue to be in East Anglia and the two southern regions, but their ratios to the national average will fall. The fall in East Anglia will take the ratio to 70. The position of Wales will improve sharply, the ratio falling from 121 to 90 .

\section{Discussion}

If the trends over the past 20 years continue there will be a large fall in premature deaths from ischaemic heart disease in England and Wales. The fall at ages over 65 years will be less. There will be a sharp worsening of the north-south divide. Mortality in the three northern and two midland regions will worsen in comparison with East Anglia and the two southern regions. In Wales death rates at younger ages have fallen sharply in successive generations and predict a continuing large fall in premature deaths. There may be additional benefits arising from the prevention project 'Heart-Beat Wales'.

Studies of both fatal and non-fatal myocardial infarction in the United States of America, Finland, Australia, and New Zealand have shown that death rates are falling and are accompanied by falls in incidence. ${ }^{5}$ Except in New Zealand, rates are falling more in younger than older age groups.

Two recent surveys of adult diet have shown that dietary fat intake does not differ greatly between one part of England and Wales and another. ${ }^{67}$ Nevertheless because of their greater susceptibility, however caused, implementation of the recommendations made by the Committee on Medical Aspects of Food Policy is more urgent 


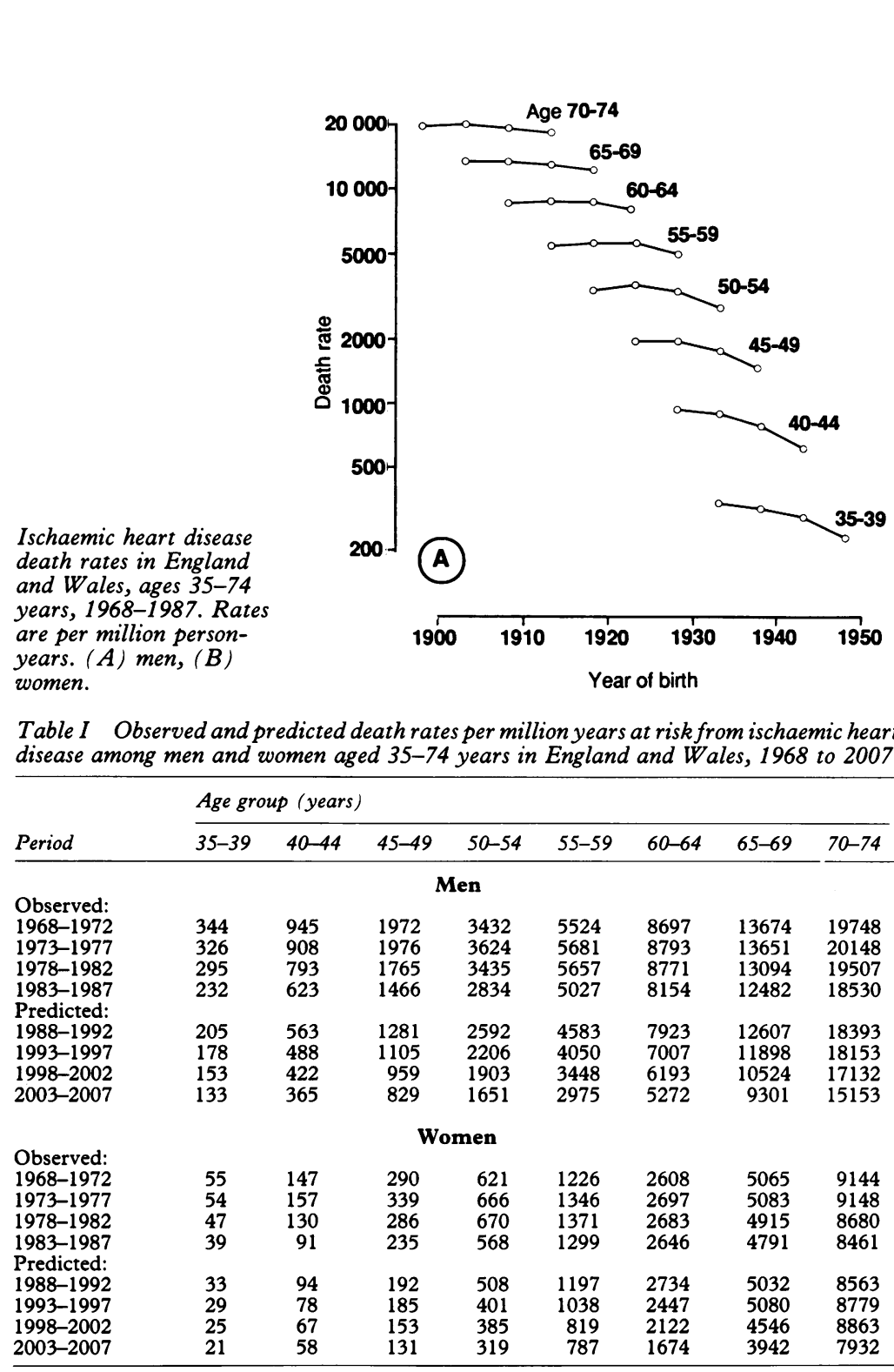

Table II Observed and predicted mortality ratios for ischaemic heart disease among men and women aged 45-64 years in the regions of England and Wales, 1968-2007

\begin{tabular}{lllll}
\hline Region & $\begin{array}{c}\text { Observed } \\
\text { in } \\
1968-77\end{array}$ & $\begin{array}{l}\text { Observed } \\
\text { in } \\
1978-87\end{array}$ & $\begin{array}{c}\text { Predicted } \\
\text { for } \\
1988-97\end{array}$ & $\begin{array}{l}\text { Predicted } \\
\text { for } \\
1998-2007\end{array}$ \\
\hline North & 121 & 124 & 128 & 128 \\
North West & 119 & 123 & 127 & 137 \\
Yorkshire and Humberside & 115 & 116 & 118 & 120 \\
East Midlands & 97 & 100 & 106 & 115 \\
West Midlands & 99 & 102 & 107 & 112 \\
East Anglia & 80 & 76 & 72 & 70 \\
South East & 87 & 85 & 82 & 80 \\
South West & 92 & 88 & 83 & 77 \\
Wales & 121 & 114 & 107 & 90 \\
\hline
\end{tabular}

among men and women in the northern and midland regions. Currently in England only around $25 \%$ of men and women aged $35-54$ years have fat intakes below the recommended $35 \%$ of total energy intake, or ratios of polyunsaturated to saturated fatty acids above the recommended $0.45 .^{6}$

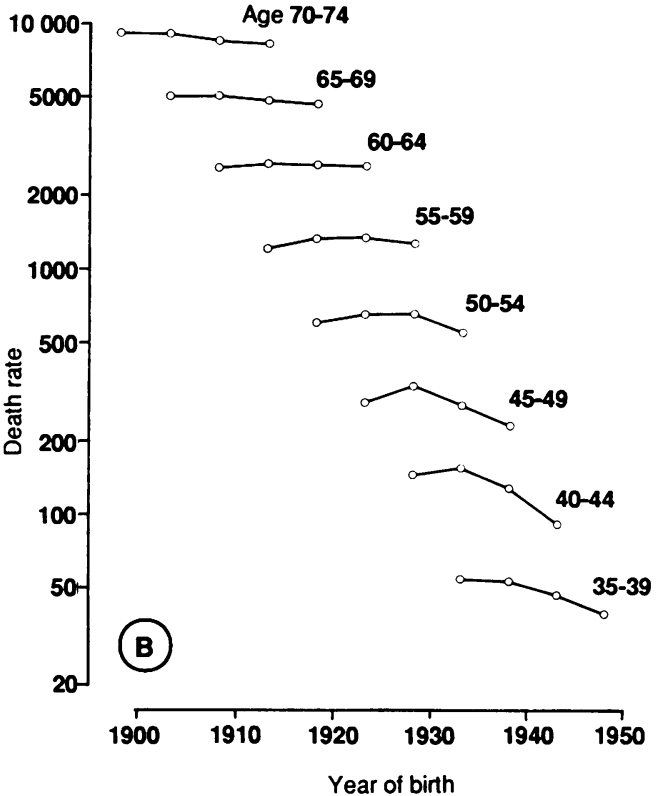

The distribution of mortality from ischaemic heart disease throughout England and Wales is closely related to the distribution of neonatal mortality 50 and more years ago. ${ }^{9}$ This indication that growth and development during prenatal life and infancy are important risk factors for the disease is supported by the results of a prospective study that showed a strong inverse relation between infant weights and death rates. ${ }^{10}$ Given the inverse relation between infant growth and ischaemic heart disease the current poor growth of young children in the inner city area of Liverpool, ${ }^{11}$ and in other northern towns such as Middlesbrough (Harland E, personal communication), must be a cause for concern. It may foreshadow regional differences in mortality that are even larger than those predicted from recent trends.

1 Registrar General. Statistical review of England and Wales. Part I: tables, medical. London: HMSO, 1968 et seg

2 Tunstall-Pedoe $\mathrm{H}$, Smith WCS, Crombie IK. Level and trends of coronary heart disease mortality in Scotland compared with other countries. Health Bull 1986; 44: 153-61.

3 Osmond C. Using age, period and cohort models to estimate future mortality rates. Int $\mathcal{f}$ Epidemiol $1985 ; 14: 124-9$.

4 Breslow NE, Day NE. The design and analysis of cohort

5 Madies. Lyon: IARC, 1987 . Trends in the incidence of myocardial infarction in Western Australia between 1971 and 1982. Am $f$ Epidemiol 1989; Australia betwe

6 Office of Population Censuses and Surveys. Dietary and nutritional survey of British adults. London: HMSO, 1990 7 Cade JE, Barker DJP, Margetts BM, Morris JA. Diet and inequalities in health in three English towns. BMF 1988; inequalities in

8 Department of Health and Social Security. Report on Health and Social Subjects 28. Diet and cardiovascular disease. London: HMSO, 1984

9 Barker DJP, Osmond C. Infant mortality, childhood nutrition, and ischaemic heart disease in England and Wales. Lancet 1986; i: 1077-81.

10 Barker DJP, Winter PD, Osmond C, Margetts BM, Simmonds SJ. Weight in infancy and death from ischaemic heart disease. Lancet 1989; ii: 577-80.

11 Hall AJ, Barker DJP, Dangerfield PH, Osmond C, Taylor JF. Small feet and Perthes' disease: a survey in Liverpool. $f$ Bone foint Surg 1988; 70-B: 611-3. 